\title{
Orofacial and dental condition in leprosy
}

\author{
Raony Môlim de Sousa Pereira ${ }^{1}$, Thalisson Saymo de Oliveira Silva ${ }^{1}$, Luciana Saraiva e Silva ${ }^{2}$, \\ Tanit Clementino Santos ${ }^{3}$, Carlos Alberto Monteiro Falcão ${ }^{1,3}$, Lucielma Salmito Soares Pinto ${ }^{2,3}$
}

\author{
'Department of Diagnosis and Clinical Dentistry, Dental School, State University of Piauí, Parnaíba, PI, Brazil \\ ${ }^{2}$ Departament of Basic Sciences, Medical School, State University of Piauí, Teresina, PI, Brazil \\ ${ }^{3}$ Department of Diagnosis and Clinical Dentistry, Dental School, UNINOVAFAPI, Teresina, PI, Brazil
}

\begin{abstract}
Aim: To verify the orofacial and dental complex in individuals affected by leprosy concerning lesions, prevalence of dental caries and biofilm storage. Methods: This study was performed on 56 patients with leprosy: 28 under treatment and 28 treated for the disease. A clinical form was prepared to include demographic and leprosy data. The prevalence of caries was analyzed using the decayed, missing, filled teeth (DMFT) index and oral hygiene was evaluated using the Plaque Control Record. The statistical significance was measured by chi-square and Student's t-test. Results: The mean age was 56.4 years, and there was predominance of males. The treatment group had more women (Pearson $\div 2=12.47, p=0.0004$ ) and younger patients (Pearson $\div 2=9.688, p=0.0079$ ) than the healed group. As much as $30.4 \%$ of patients had orofacial complaints related to the disease. The most often observed variations of normality as racial melanin pigmentation $(67.8 \%)$ and lingual varices $(32.1 \%)$, and lesions such as atrophy of the anterior nasal spine (25\%), inflammatory papillary hyperplasia (17.8\%), and collapse of the nasal bridge (14.3\%). There were no specific oral lesions among leprosy patients. The mean DMFT was 20.8 and the Plaque Control Record was $70.2 \%$. The treated group had higher DMFT than the treatment group (Student's $t p=0.003$ ). Conclusions: The oral health status of individuals with leprosy is poor, with high levels of plaque and DMFT. No oral lesions associated with the disease were seen.
\end{abstract}

Keywords: leprosy, Mycobacterium leprae, oral health.

Received for publication: September 25, 2013 Accepted: December 03, 2013

Correspondence to: Lucielma Salmito Soares Pinto Centro Universitário de Saúde Ciências Humanas e Tecnológicas do Piauí UNINOVAFAPI, Faculdade de Odontologia Rua Vitorino Orthigues Fernandes, 6123 CEP: $64073-505$

Bairro Uruguai, Teresina, PI, Brasil Phone: +55 8621060712

E-mail: lucielma@yahoo.com.br

\section{Introduction}

Leprosy is a chronic infectious disease with interpersonal transmission caused by Mycobacterium leprae, a microorganism that has an affinity for the skin and peripheral nerves and, in more advanced stages affects internal organs and mucous membranes, with a high potential for causing physical disability ${ }^{1-4}$. It is present in less developed countries and most often affects the population with low socioeconomic status. With variable prevalence, India and Brazil are respectively the first and second countries with the highest number of leprosy cases ${ }^{1,5}$. The Pan American Health Organization (PAHO) includes leprosy in the group of neglected diseases and other poverty-related infections, and considers it a public health problem ${ }^{6}$.

The prevalence rate of leprosy in Brazil, an indicator that monitors the progress towards elimination of this disease as a public health problem, had a gradual reduction in recent years. This reduction results from the decrease in the number of new cases of the disease, the shorter treatment time and the improvement of 
information systems. The prevalence rate of leprosy in Brazil in 2012 was 1.51 cases per 10,000 inhabitants, which represents a decrease of $12 \%$ compared to the value of this coefficient in 2004. Despite these advances, the spatial distribution of leprosy remains the same in the country, with coefficients still high in the cities of Northern and Northeastern Brazil ${ }^{6}$.

Despite the oral examination being part of the comprehensive examination of a patient with leprosy, there are few studies describing the oral health and dental care of these patients. Unlike the cutaneous manifestations of the disease, which are well documented in the literature, descriptions of oral findings are scarcely detailed, making comparisons difficult, and old if the treatment of the disease was not effective $e^{2-4,7,8}$. It is important that the dentist be aware of the reactions caused by leprosy in the orofacial complex. Thus, the present study aimed to evaluate the oral health status of patients with leprosy in relation to the presence of associated lesions, prevalence of caries and plaque accumulation.

\section{Material and methods}

The sample consisted of 56 patients of both genders with a history of leprosy: 28 under treatment and 28 were already treated for the disease. The patients were recruited from the Hospital Colônia do Carpina and Basic Health Units in the city of Parnaíba, PI, Brazil in 2011 and 2012. The study was conducted in accordance with the Declaration of Helsinki guidelines and was approved by the Ethics Committee of UNINOVAFAPI (0269.0.043.000-10 Protocol). All patients gave written informed consent to participate in the study.

A clinical form containing the data was filled for each patient, as follows: demographic data, type and duration of leprosy, treatment adopted for leprosy, and complaints about the disease. Facial and oral examinations were performed. The prevalence of caries was analyzed using the decayed, missing, filled teeth (DMFT) index as recommended by the World Health Organization (WHO). Oral hygiene was evaluated using the Plaque Control Record by O'Leary, which was obtained by the examination of four dental surfaces of all teeth and included the percentage of tooth surfaces with dental plaque9.

Leprosy diagnosis was carried out according to WHO criteria $^{1}$. Biopsies, histopathological examinations, smears, and photographic registration were undertaken as required. The SPSS software version 18.0 (SPSS Inc., Chicago, IL, USA) was used and the statistical significance was analyzed by Pearson's chi-square test and Student's t-test.

\section{Results}

Fifty-six patients were evaluated, 28 under treatment and 28 treated patients. The mean and median age was 56.4 years and 58.5, respectively, ranging from 23 to 83 years. The treatment group had a mean age of 51.4 and the treated group had a mean age of 61.2 years. The treated group had patients older than the treatment group (Pearson $\div 2=9.688 ; \mathrm{p}=0.0079$ ). Out of all analyzed patients, 33 $(58.9 \%)$ were male; however, the treatment group showed

Table 1 - Distribution of gender and age among disease groups

\begin{tabular}{|c|c|c|c|c|c|c|c|c|}
\hline \multirow{2}{*}{\multicolumn{2}{|c|}{ Variable }} & \multicolumn{2}{|c|}{$\begin{array}{l}\text { Under } \\
\text { treatment }\end{array}$} & \multicolumn{2}{|c|}{ Treated } & \multicolumn{2}{|c|}{ Total } & \multirow{2}{*}{$\mathrm{p}^{*}$} \\
\hline & & $n$ & $\%$ & $n$ & $\%$ & $n$ & $\%$ & \\
\hline \multirow{3}{*}{ Gender } & Male & 10 & 35.7 & 23 & 82.1 & 33 & 58.9 & \multirow{3}{*}{$\begin{array}{l}x^{2}=12.47 \\
p=0.0004\end{array}$} \\
\hline & Female & 18 & 64.3 & 5 & 17.9 & 23 & 41.1 & \\
\hline & Total & 28 & 100.0 & 28 & 100.0 & 56 & 100.0 & \\
\hline \multirow{4}{*}{$\begin{array}{c}\text { Age } \\
\text { groups } \\
\text { (years) }\end{array}$} & $23-40$ & 9 & 32.1 & 1 & 3.6 & 10 & 17.9 & \multirow{4}{*}{$\begin{array}{l}x^{2}=9.688 \\
p=0.0079\end{array}$} \\
\hline & $41-60$ & 11 & 39.3 & 10 & 35.7 & 21 & 37.5 & \\
\hline & $61-83$ & 8 & 28.6 & 17 & 60.7 & 25 & 44.6 & \\
\hline & Total & 28 & 100.0 & 28 & 100.0 & 56 & 100.0 & \\
\hline
\end{tabular}

${ }^{*}$ Pearson Chi-square

greater prevalence of women (Pearson $\div 2=12.47$; $\mathrm{p}=0.0004)$ (Table 1).

Among patients with ongoing disease, 16 (57.14\%) had lepromatous or multibacillary type leprosy and 12 $(42.86 \%)$ had tuberculoid or paucibacillary. Orofacial complaints were reported by $17(30.4 \%)$ patients: nodules, swelling, ulcers, spots on the face and ears, loss of the nasal bridge and spine; ulcers and nodules in the tongue and gingiva, as well as tooth weakness. Most patients $(n=42$, $75 \%$ ) reported following proper hygiene measures regarding toothbrushing and doing it with minimum frequency of three times a day; however, dental floss was not used by any individual. Fifty-three subjects $(94.6 \%)$ denied having received specific dental guidance after diagnosis. Alcoholism and smoking were reported by $29(51.7 \%)$ respondents. Twenty-two subjects $(39.3 \%)$ reported at least one family member with a history of the disease.

Physical examination revealed orofacial variations of normality, with 38 cases of melanin pigmentation $(67.8 \%)$ and 18 cases of lingual varices $(32.1 \%)$, whereas among the lesions were seen most frequently: atrophy of the nasal spine $(25 \%)$, inflammatory papillary hyperplasia $(17.8 \%)$ and collapse of the nasal bridge $(14.3 \%)$. Prevalence of normality variations and non-specific lesions, candidiasis and inflammatory papillary hyperplasia, showed no significant difference between groups. However, the lesions associated with leprosy were more prevalent in the healed group. There were no specific oral lesions of leprosy among the evaluated patients (Table 2).

The overall mean DMFT was 20.8; in the group of treated patients it was 23.8 and among patients under treatment, it 17.8 (Student's t; $\mathrm{p}=0.003$ ). The mean Plaque Control Record was 70.2\%; among the healed patients it was $75.3 \%$ and $66.6 \%$ in under treatment subjects (Student's $\mathrm{t} ; \mathrm{p}=0.297$ ) (Table 3). 
Table 2 - Distribution of orofacial findings among the groups.

\begin{tabular}{|c|c|c|c|c|c|c|c|}
\hline & \multirow{2}{*}{ Variable } & \multicolumn{2}{|c|}{$\begin{array}{l}\text { Under } \\
\text { treatment }\end{array}$} & \multicolumn{2}{|c|}{ Treated } & \multicolumn{2}{|c|}{ Total } \\
\hline & & $\mathrm{n}$ & $\%$ & $\mathrm{n}$ & $\%$ & $\mathrm{n}$ & $\%$ \\
\hline \multirow{6}{*}{$\begin{array}{l}\text { Variations } \\
\text { of normality }\end{array}$} & Melanin pigmentation & 19 & 42.2 & 19 & 52.8 & 38 & 46.9 \\
\hline & Ligual varices & 11 & 24.4 & 7 & 19.4 & 18 & 22.2 \\
\hline & Fissured tongue & 7 & 15.6 & 4 & 11.1 & 11 & 13.6 \\
\hline & Fordyce's granules & 7 & 15.6 & 3 & 8.3 & 10 & 12.3 \\
\hline & Smoker's melanosis & 1 & 2.2 & 3 & 8.3 & 4 & 4.9 \\
\hline & Total & 45 & 100.0 & 36 & 100.0 & 81 & 100.0 \\
\hline \multirow{3}{*}{$\begin{array}{l}\text { Non- } \\
\text { specific } \\
\text { lesions, }\end{array}$} & $\begin{array}{c}\text { Inflammatory papillary } \\
\text { hyperplasia }\end{array}$ & 7 & 87.5 & 3 & 50.0 & 10 & 71.4 \\
\hline & Candidiasis & 1 & 12.5 & 3 & 50.0 & 4 & 28.6 \\
\hline & Total & 8 & 100.0 & 6 & 100.0 & 14 & 100.0 \\
\hline \multirow{8}{*}{$\begin{array}{l}\text { Specific } \\
\text { lesions }\end{array}$} & $\begin{array}{l}\text { Atrophy of the nasal } \\
\text { spine }\end{array}$ & 0 & 0.0 & 14 & 42.4 & 14 & 32.6 \\
\hline & $\begin{array}{c}\text { Collapse of the nasal } \\
\text { bridge }\end{array}$ & 0 & 0.0 & 8 & 24.2 & 8 & 18.6 \\
\hline & $\begin{array}{l}\text { Yellowish or reddish } \\
\text { facial spots }\end{array}$ & 5 & 50.0 & 1 & 3.0 & 6 & 14.0 \\
\hline & Loss of eyebrows & 0 & 0.0 & 5 & 15.2 & 5 & 11.6 \\
\hline & $\begin{array}{c}\text { Auricular spots or } \\
\text { nodules }\end{array}$ & 2 & 20.0 & 3 & 9.1 & 5 & 11.6 \\
\hline & Facial nodules & 3 & 30.0 & 0 & 0.0 & 3 & 7.0 \\
\hline & Absent uvula & 0 & 0.0 & 2 & 6.1 & 2 & 4.7 \\
\hline & Total & 10 & 100.0 & 33 & 100.0 & 43 & 100.0 \\
\hline
\end{tabular}

Table 3 - Distribution of the DMFT and Plaque Control Record index among disease groups.

\begin{tabular}{|c|c|c|c|c|}
\hline Index & Age (years) & $\begin{array}{c}\text { Under } \\
\text { treatment }\end{array}$ & Treated & $\mathrm{p}^{*}$ \\
\hline \multirow{4}{*}{ DMFT } & $23-40$ & 8.3 & 20 & \multirow{4}{*}{0.003} \\
\hline & $41-60$ & 19.7 & 20.9 & \\
\hline & $61-83$ & 25.9 & 25.7 & \\
\hline & $23-83$ & 17.8 & 23.8 & \\
\hline \multirow{4}{*}{$\begin{array}{c}\text { Plaque Control } \\
\text { Record (\%) }\end{array}$} & $23-40$ & 72.7 & 49.3 & \multirow{4}{*}{0.297} \\
\hline & $41-60$ & 69.1 & 67.3 & \\
\hline & $61-83$ & 40.6 & 90.4 & \\
\hline & $23-83$ & 66.6 & 75.3 & \\
\hline
\end{tabular}

*Student's $\mathrm{t}$ test

\section{Discussion}

This study evaluated 56 patients with leprosy, 28 treated and 28 in treatment. The treatment group had a mean age of 51.4 years, agreeing with the literature that describes average ages 35.9 to 53 years for patients at diagnosis or during multidrug therapy ${ }^{3,10-14}$. The group of healed patients had a mean age of 61.2 years. The significantly larger number of treated seniors in the group can be understood considering that the treatment of leprosy is long-lasting and there are frequent dropouts and interruptions in its course, resulting in a longer healing time ${ }^{14}$.

The disease affected a larger number of men, except in the group under treatment, in which $64.3 \%$ of patients were women, with a statistically significant difference. The literature shows a higher prevalence in $\operatorname{men}^{3,8,11,12,15}$, though some authors describe more cases in women ${ }^{10,16}$. Due to a higher risk of exposure, men are usually more affected, but the gender ratio 
has declined in the past few years ${ }^{17}$. Still, $39.3 \%$ of respondents had at least one family member with the disease living in the same household, which shows the importance of family contact as a source of the disease spreading, evidenced by the presence of anti-PGL-1 in household contacts $^{18,19}$.

Most patients with active disease had multibacillary leprosy $(57.14 \%)$, usually seen in older individuals or with decreased immune resistance, reflecting a greater spread of the bacillus in the body. Leprosy is a chronic infection with diverse clinical presentations that vary according to the individual's immune response. The two ends of this spectrum correspond to the forms tuberculoid (paucibacillary) and lepromatous (multibacillary). The first is characterized by a more intense immune response, fewer skin lesions and few bacilli in tissue specimens. The lepromatous form displays a relatively anergic state, and often occurs in patients with reduced cell-mediated immune response. There is a group called borderline, with less common forms and intermediate lesions. The main clinical features of the disease are hypopigmented or reddish spots on the skin with loss of sensitivity, involvement of peripheral nerves, and muscle weakness. They involve most often the skin, nerves, and mucosa of the upper respiratory $\operatorname{tract}^{3,20}$.

Orofacial complaints during the course of the disease were common, being reported by $30.4 \%$ of the patients. According to the perception of individuals, were reported lesions such as nodules and stains on the face, as well as sequelae of the disease, particularly affecting the nasal structure. The perception is the personal interpretation concerning his/her health status, involving objective and subjective factors. Due to the great potential of developing visible deformities that affect areas of the face, it is important to highlight that leprosy's impacts are not only physical, but also psychological ${ }^{21}$.

The extraoral examination revealed changes associated with leprosy such as collapse of the nasal bridge (32.6\%), atrophy of the nasal spine (18.6\%), spots on the face (14\%), and loss of eyebrows (11.6\%). The typical face of leprosy includes atrophy of the anterior nasal spine, atrophy and recession of the alveolar process of the premaxilla, and endonasal inflammatory reactions ${ }^{12}$. Other manifestations such as facial nerve involvement, eye injuries, and facial deformity have also been described ${ }^{3}$. Significantly, higher prevalence of changes observed in the healed group was mainly the disease sequelae. Patients treated for a longer time, as in the present study, particularly until the 1980s, underwent monotherapy with dapsone or were confined in colonies. Many had the disease for a long period without the correct diagnosis, resulting in greater exposure to the bacillus and consequently numerous sequels ${ }^{8}$.

Variations of normality were observed by the intraoral examination: melanin pigmentation (46.9\%), lingual varices (22.2\%), fissured tongue (13.6\%), Fordyce granules (12.3\%) and smoker's melanosis $(4.9 \%)$. Common injuries were also noticed, such as inflammatory papillary hyperplasia associated with the use of prosthesis (71.4\%) and candidiasis (28.6\%).
No specific leprosy lesion was perceived within the oral cavity. Agreeing with these findings, other authors in similar studies observed fissured tongue, candidiasis, inflammatory papillary hyperplasia, fibroma, traumatic ulceration. However, there were no lesions caused by $M$. leprae in the oral cavity, as reported in the literature ${ }^{7,8,10,15}$. The absence of specific leprosy lesions may be attributed to the natural scarcity of $M$. leprae in the oral mucosa, when compared to the colder places of the $\operatorname{skin}^{7}$, as well as the scarcity provided by the action of multidrug therapy, since the patients were under treatment $t^{7,8,10,15}$. However, the $M$. leprae genome was identified by polymerase chain reaction in oral mucosa of patients even during treatment ${ }^{22}$.

Oral lesions are characteristic of advanced disease. They are rare, especially in the tuberculoid form; however, they may be recognized in about $20-60 \%$ of cases in the lepromatous type $\mathrm{e}^{2,3,12,20}$. They are usually asymptomatic and may vary between yellowish spots or reddish papules or nodules that may develop sessile tissue necrosis and ulceration ${ }^{4,12}$. Hard and soft palate, uvula, tongue belly, lips, and gingiva are prevailing affections, in addition to the destruction of the anterior maxilla and tooth $\operatorname{loss}^{12}$. It is noteworthy that clinical abnormalities of the oral cavity in patients with leprosy do not imply in a specific lesion of the disease, but there is need for histopathological confirmation. Moreover, even in patients with normal clinical appearance, it is possible to see specific histopathological disease signs ${ }^{2}$.

The mean DMFT value found among all study subjects was 20.8, considered very high. A higher mean DMFT was observed with increasing age. The range of 41 to 60 years had mean DMFT of about 20 and from 61 to 83 years, around 25 in both groups, so there was no statistically significant difference when considering each age group. The age range of 23 to 40 years had this analysis compromised since the group had only one healed patient. The mean DMFT in the group of cured patients was 23.8 and 18 in the treatment group, with a statistically significant difference between them. This may be attributed to the difference between the age groups, due to the higher number of elderly individuals in the healed group, which eventually raised the mean DMFT of this group. The results of the National Oral Health Project (SB Brazil 2010) indicate mean DMFT of 17.83 and 28.47 for the age groups 35-44 years and 65-74 years, respectively, considering the values for Northeastern Brazil ${ }^{23}$. Thus, although the results are bad, they do not differ from the Brazilian reality for the general population in that region, agreeing with Souza ${ }^{8}$.

During the interview, $75 \%$ of patients reported brushing their teeth at least three times a day, despite not using dental floss. Still, average rates of Plaque Control Record of $70.2 \%$ were observed. Indexes above $20 \%$ are associated with poor oral hygiene (9). The lack of specific dental guidance reported by $94.6 \%$ of patients, may be responsible for the accumulation of dental plaque evidenced in this study. Despite the high frequency of reported toothbrushing, people do not always use the correct technique, which may reflect in a poor dental condition ${ }^{24}$. 
It may be concluded that the oral health status of individuals treated and healed from leprosy is poor, with high levels of plaque and DMFT. Additionally, variations of normality and common oral lesions were seen, such as candidiasis and inflammatory papillary hyperplasia. The patients did not present leprosy-specific lesions. Nevertheless, the situation shown in the present study cannot be considered worse than the one of the general population in Northeastern Brazil. Better methods of oral hygiene and regular dental monitoring should be adopted in order to increase the quality of life of these patients.

\section{References}

1. WHO. Expert Committee on Leprosy, 8th Report. WHO, Technical Report Series 968, 2012.

2. Abreu MAMM, Michalany NS, Weckx LLM, Pimentel DRN, Hirata $\mathrm{CHW}$, Alchorne MMA. The oral mucosa in leprosy: a clinical and histopathological study. Rev Bras Otorrinolaringol. 2006; 72: 312-6.

3. Taheri JB, Mortazavi H, Moshfeghi M, Bakhshi M, Bakhtiari S, AzariMarhabi $S$ et al. Oro-facial manifestations of 100 leprosy patients. Med Oral Patol Oral Cir Bucal. 2012; 17: 728-32.

4. Pallagatti S, Sheikh S, Kaur A, Aggarwal A, Singh R. Oral cavity and leprosy. Indian Dermatol Online J. 2012; 3: 101-4.

5. Alencar CH, Ramos AN Jr, dos Santos ES, Richter J, Heukelbach J. Clusters of leprosy transmission and of late diagnosis in a highly endemic area in Brazil: focus on different spatial analysis approaches. Trop Med Int Health. 2012; 17: 518-25.

6. Brazil. Ministry of Health. Epidemiological Bulletin. Epidemiological situation of leprosy in Brazil - analysis of the selected last decade indicators and challenges for disposal. 2013; 44.

7. Santos GG, Marcucci G, Marchese LM. Oral aspects of specific and unspecific lesions in Hansen's disease patients. Pesqui Odontol Bras. 2000; 14: 268-272.

8. Souza VA, Emmerich A, Coutinho EM, Freitas M, Silva EH, Merçon FG et al. Dental and oral condition in leprosy patients from Serra, Brazil. Lepr Rev. 2009; 80: 156-163.

9. Buczkowska-Radliñska J, Pol J, Szmidt M, Biñczak-Kuleta A. The influence of polymorphism of the MUC7 gene on the teeth and dental hygiene of students at a faculty of dentistry in Poland. Postepy Hig Med Dosw. 2012; 19: 204-9.

10. De Araújo Navas EA, Inocêncio AC, Almeida JD, Back-Brito GN, Mota $\mathrm{AJ}$, Jorge $\mathrm{AO}$ et al. Oral distribution of Candida species and presence of oral lesions in Brazilian leprosy patients under multidrug therapy. J Oral Pathol Med. 2009; 38: 764-7.

11. Dave B, Bedi R. Leprosy and its dental management guidelines. Int Dent J. 2013; 63: 65-71.

12. Rawlani SM, Rawlani S, Degwekar S, Bhowte RR, Motwani M. Oral health status and alveolar bone loss in treated leprosy patients of central India. Indian J Lepr. 2011; 83: 215-24.

13. Motta ACF, Furini RB, Simão JCL, Vieira MB, Ferreira MAN, Komesu $M C$ et al. Could leprosy reactions episodes be exacerbated by oral infections? Rev Soc Bras Med Trop. 2011; 44: 633-5.

14. Heukelbach J, André Chichava O, de Oliveira AR, Häfner K, Walther F, de Alencar $\mathrm{CH}$ et al. Interruption and defaulting of multidrug therapy against leprosy: population-based study in Brazil's Savannah Region. PLoS Negl Trop Dis. 2011; 5: 1031-9.

15. Martins MD, Russo MP, Lemos JB, Fernandes KP, Bussadori SK, Corrêa CT et al. Orofacial lesions in treated southeast Brazilian leprosy patients: a cross-sectional study. Oral Dis. 2007; 13: 270-3.

16. Gomes CCD, Gonçalves HS, Pontes MAA, Penna GO. Clinical and epidemiological profile of patients diagnosed with leprosy in a reference center in the northeast of Brazil. An Bras Dermatol. 2005; 80: 283-8.
17. Monteiro LD, Alencar CHM, Barbosa JC, Braga KP, Castro MD, Heukelbach J. Physical disabilities in leprosy patients after discharge from multidrug therapy in Northern Brazil. Cad Saude Publica. 2013; 29 : 909-20.

18. Cardona-Castro N, Beltrán-Alzate JC, Manrique-Hernández R. Survey to identify Mycobacterium leprae-infected household contacts of patients from prevalent regions of leprosy in Colombia. Mem Inst Oswaldo Cruz. 2008; 103: 332-6.

19. Bazan-Furini R, Motta AC, Simão JC, Tarquínio DC, Marques W, Barbosa $\mathrm{MH}$ et al. Early detection of leprosy by examination of household contacts, determination of serum anti-PGL-1 antibodies and consanguinity. Mem Inst Oswaldo Cruz. 2011; 106: 536-540.

20. Ghosh S, Gadda RB, Vengal M, Pai KM, Balachandran C, Rao R et al. Oro-facial aspects of leprosy: report of two cases with literature review. Med Oral Patol Oral Cir Bucal. 2010; 15: 459-62.

21. Almeida JRS, Alencar CH, Barbosa JC, Dias AA, Almeida MEL. Selfperception of people afflicted with leprosy regarding their oral health and the need for treatment. Cien Saude Coletiva. 2013; 18: 817-26.

22. Santos GG, Marcucci G, Guimarães Júnior J, Margarido LC, Lopes LHC. Molecular detection of Mycobacterium leprae by polymerase chain reaction in oral mucosa biopsy specimens. An Bras Dermatol. 2007; 82: 245-9.

23. Brazil. [Department of Primary Care. Department of Health Care Project SB Brazil 2010: National Oral Health Survey - main results. Brasilia: Ministry of Health], 2011.Portuguese.

24. Belmonte PCR, Virmond MCL, Tonello AS, Belmonte GC, Monti JFC. Characteristics of periodontal disease in leprosy. Bol Epidemiol Paulista. 2007; 4: 4-9. 